\title{
HISTORIČNA GLASBILA V POUSTVARJALNI PRAKSI MOŽNOSTI IN PERSPEKTIVE V SLOVENSKI GLASBENI KULTURI
}

\author{
DARJA KOTER \\ Akademija za glasbo Univerze v Ljubljani
}

Izvleček: Aktualno izvajanje stare glasbe je tesno povezano s proučevanjem nekdanjih poustvarjalnih praks, z ohranjanjem historičnih glasbil, delovanjem specializiranih ansamblov in izobraževanjem. Bistveno vlogo pri tem razvoju na Slovenskem imajo muzejske zbirke glasbil, nacionalni programi za oživljanje kulturne dediščine ter posamezne kulturne in izobraževalne ustanove. V danih pogojih je potrebno izhajati iz primerov dobrih praks ter iskati in razvijati nove možnosti, ki bi jih bilo potrebno iskati $v$ glasbenih zbirkah slovenskih muzejev in na področju visokega glasbenega šolstva.

Ključne besede: zbirke glasbil, historična glasbila, historična izvajalska praksa

\begin{abstract}
The interpretation and performance of early music are closely related to the research of historical performance practices, the preservation of historical musical instruments, activities / endeavours of specialized ensembles and education. This area of research in Slovenia is largely led by museum collections of musical instruments, national programmes for the revitalization of cultural heritage and some cultural and educational institutions. It is therefore essential to consider examples of good practice and to develop new opportunities regarding collections of musical instruments in Slovene museums, early music festivals and music education.
\end{abstract}

Keywords: collections of instruments, historical instruments, historical performance practice

V prispevku se posvečamo razmišljanju o pojavnih oblikah in možnostih izvajalske prakse na historičnih glasbilih iz slovenskih muzejev v preteklosti, sedanjosti in prihodnosti. ${ }^{1}$ To je namreč področje poustvarjanja, ki je na Slovenskem manj razvito, kot bi bilo glede na možnosti pričakovano, pri čemer izvzemamo problematiko izvajanja na orgelskih instrumentih v slovenskih cerkvah in posamezna znana glasbila zasebnikov, kar bi zahtevalo samostojno obravnavo. Iztočnice za pričujoča razmišljanja narekujejo vzporednice s svetovnim prostorom, kjer se je zanimanje za proučevanje nekdanjih glasbenih praks in posledično zbiranje, ohranjanje in izvajanje na starih glasbilih začelo v 19. stoletju. ${ }^{2} \mathrm{Na}$ Slovenskem je bilo drugače: zavedanje o pomenu ohranjanja starih glasbil v muzejskih

1 Projekt št. P6-0376 je sofinancirala Javna agencija za raziskovalno dejavnost Republike Slovenije iz državnega proračuna.

2 Navajam izbor literature: Dolmetsch, The Interpretation of the Music of the 17th and 18th Centuries Revealed by Contemporary Evidence; Donington, The Interpretation of Early Music; 
zbirkah je dokazano od konca 19. stoletja, medtem ko se je historična izvajalska praksa na posameznih eksponatih pojavila proti koncu 20. stoletja. ${ }^{3}$ Odtlej sicer narašča, vendar neskladno z možnostmi, ki jih ponuja kulturna dediščina. Najpomembnejše vzroke za takšno stanje lahko najdemo v pomanjkanju poznavanja glasbene dediščine, skromni dinamiki restavriranja in promoviranja muzejskih zbirk in posameznih instrumentov ter v glasbenem šolstvu, ki bi ob izvajanju ustreznih študijskih programov lahko vplivalo na poustvarjalne možnosti in posledično na promocijo glasbene dediščine. K izbiri tematike nas spodbuja nedavna raziskava, opravljena v slovenskih muzejih, ki je opozorila na stanje in pomen muzejskih glasbil in ne nazadnje na neizkoriščene možnosti njihove javne rabe. ${ }^{4}$ Ugotovitve kažejo, da so med muzejskimi glasbili posamezna vitalno ohranjena, primerna za koncertno dejavnost ter pomembna za slovensko in mednarodno kulturno dediščino. Raziskava je med drugim opozorila na problematiko restavriranja in ustreznega rokovanja z glasbenimi eksponati ter na to, da so v glasbenih zbirkah tudi takšni instrumenti, ki bi bili ob ustreznih restavratorskih posegih prav tako primerni za umetniško poustvarjalnost. Nove ugotovitve narekujejo kritični pogled na neizkoriščene možnosti igranja na historičnih instrumentih, ki je v svetu že dolgo uveljavljeno in privzeto kot pomemben del umetniških praks. Prav tako je znano dejstvo, da skladno z razvojem poustvarjanja na starih glasbilih in njihovih replikah narašča tudi raziskovanje nekdanjih izvajalskih praks in izobraževanje v igranju na historična glasbila. Če je vsesplošna globalizacija prinesla neverjetne možnosti dostopa do znanstvenih raziskav na vseh področjih, tudi na polju proučevanja glasbenih in estetskih značilnosti starejših obdobij, smo na stopnji visokošolskega izobraževanja v smislu poustvarjanja na historičnih instrumentih šele na začetku poti, čeprav se je le-to v svetu uveljavilo že več kot pol stoletja nazaj.

$\mathrm{V}$ zadnjem času so se v določenih glasbenih krogih pojavila razmišljanja in dileme o možnostih poustvarjanja na glasbilih, ki sodijo v slovensko kulturno dediščino. Pri nas se namreč v zadnjih dvajsetih letih povečuje število koncertov in festivalskih prireditev, posvečenih tako imenovani stari glasbi, pri tem pa opažamo, da razen izjemoma na glasbenih odrih niso prisotna glasbila iz slovenskih muzejev. Ker je ta dediščina dokaj bogata in deloma tudi restavrirana in prezentirana na muzejskih razstavah, se pojavlja vprašanje, zakaj med poustvarjalci ni dovolj opažena. Poznamo pa tudi posamezne primere, iz katerih lahko povzamemo, da se nekateri glasbeniki obračajo na muzeje z željo po igranju na historična glasbila, vendar se pogosto ne zavedajo omejitev, ki jih narekuje skrb za glasbeno dediščino. Aktualna dogajanja so vnela razprave o tovrstni problematiki in prinesla določene pobude. Muzejska stroka se pretežno zavzema za to, da se s posebnimi pravilniki določi pogoje, pod katerimi bi bilo mogoče posamezne eksponate uporabljati v javne namene, jih morda tudi izposojati ali kako drugače prezentirati v smislu njihovega zvoka. Spet drugi, predvsem akterji koncertnega poustvarjanja in nekateri organizatorji festivalov za staro glasbo, si predstavljajo izposojo in rabo glasbil nekoliko bolj poenostavljeno. Predvsem je opazno pomanjkljivo zavedanje o občutljivosti in krhkosti glasbil iz muzejskih zbirk ter o tem, da je za nekatere med njimi dolgotrajno

Dreyfus, »Early Music defended against its devotees«; Kenyon, ur., Authenticity and early music; Lawson in Stowell, The Historical Performance of Music.

3 Koter, Glasbilarstvo na Slovenskem, 7-9.

4 Prim. Koter, Ekspertiza o stanju in možnostih javne prezentacije glasbil v slovenskih muzejih. 
igranje neprimerno, celo škodljivo. Prav zato se je na podlagi slabih izkušenj v svetu uveljavila praksa izdelovanja replik, ki ponuja prepričljivo nadomestilo originalom. V tej smeri so razmišljali tudi v Pokrajinskem muzeju Ptuj-Ormož, ko so pred dobrimi desetimi leti poskrbeli za repliko muzejske lutnje Andreasa Beera iz leta 1694, ki je rariteta prve vrste, vendar zaradi številnih poškodb v preteklosti neprimerna za igranje. Zaradi omenjene problematike je bila v okviru Ministrstva za kulturo Republike Slovenije nedavno ustanovljena komisija, ki bo na podlagi omenjene ekspertize izdelala pravilnik oziroma navodila muzejem, kako ravnati z eksponati za javno rabo. Ugotovitve kažejo, da so pomembnejši glasbeni eksponati del zbirk Pokrajinskih muzejev Ptuj-Ormož, Maribor, Celje in Koper, Narodnega muzeja Slovenije, Posavskega muzeja Brežice in Pomorskega muzeja Sergej Mašera Piran. Iz analize omenjene ekspertize je razvidno, da v nobenem od muzejev z glasbili ni ustrezno usposobljenih kustosov ali drugega osebja, ki bi lahko relevantno odločalo o javni rabi glasbil, njihovi izposoji in/ali restavriranju. Problematika narekuje razmišljanje o zaposlovanju kustosov z ustrezno glasbeno izobrazbo oziroma tutorstvu nad glasbenimi eksponati, s čimer bi bila omogočena strokovna zaščita historičnih glasbil, presoja o možnostih restavriranja in igranja. V teh okvirih obstaja zgolj ena izjema, in sicer v Pomorskem muzeju Sergej Mašera, ki poseduje violino, nekoč v lasti Giuseppa Tartinija. Med leti 1715 in 1725 jo je izdelal pater Dom Nicolò Amati in je eno najpomembnejših godal v slovenski dediščini. Tutorstvo nad violino je - sicer neformalno - prevzel goslar svetovnega slovesa Bruce Carlson, delujoč v Cremoni, ki je v piranskem muzeju svetovalec o vseh vprašanjih ravnanja $z$ violino. Tartinijeva violina je eden boljših primerov oživljanja kulturne dediščine pri nas, saj je primerno restavrirana, uigrana, ob določenem varstvenem režimu pa jo je mogoče za koncertno dejavnost tudi izposojati. ${ }^{5}$

Iz analize arhivskega gradiva slovenskih muzejev je razvidno, da so posamezne ustanove v preteklih letih (med leti 1988 in 2003) nekatera pomembnejša glasbila (godala, orgle, klavirje, klavikorde idr.) ustrezno restavrirale in jih tudi javno predstavile na muzejskih koncertih. Primeri dobre prakse so pokazali, da so lahko glasbeni eksponati odličen promotor slovenske dediščine, kajti koncerti, studijska snemanja in druge oblike zvočnih zapisov so bistveno pripomogli k njeni promociji in prepoznavnosti v domačem in mednarodnem merilu. Zgovoren primer je viola d'amore praškega izdelovalca Johannesa Udalricusa Eberleta iz leta 1732, ohranjena v Pokrajinskem muzeju Ptuj-Ormož. Viola d'amore je glasbilo z dokaj kratko zgodovino, zato so ohranjeni primerki redki. Na Slovenskem je to edini praktično intaktno ohranjen instrument. Po obliki sodi v družino viol, ki je tekom 17. stoletja razvila številne inačice v različnih uglasitvah. Klasično oblikovana viola d'amore $\mathrm{z}$ ravnim resonančnim dnom in visokimi rameni, ki preidejo $\mathrm{v}$ dokaj dolgo ubiralko in nato $\mathrm{v}$ vijačnico $\mathrm{z}$ rezbarjeno glavico, ima umetelno rozeto in 7 strun za igranje. Pod njimi teče 7 tankih kovinskih - simpatetičnih strun, uglašenih oktavo višje, ki pri igranju sozvenijo in dajo glasbilu posebno mehak ton. To je eden izmed razlogov za poimenovanje glasbila, ki je simbolno dopolnjeno z izrezljano amorjevo glavico z zavezanimi očmi kot sinonim za slepo ljubezen. Izdelovalec J. U. Eberle (1699-1768) je bil zelo cenjen praški mojster strunskih glasbil, čigar primerke hranijo

5 Prim. Pomorski muzej Sergej Mašera Piran, dokumentacija iz arhiva Kulturnozgodovinskega oddelka. 
največji muzeji glasbil na svetu. ${ }^{6}$ Ptujski muzej se je med leti 1988 in 2003 intenzivno posvečal restavriranju in prezentaciji glasbil, v posameznih primerih pa je poskrbel tudi za koncertno izvajanje in arhiviranje audio posnetkov. Pri tem se je soočil s problematiko velike vrzeli na tem področju, kar je narekovalo povabilo izvajalcev iz tujine. Čeprav so bila prizadevanja ustanove medijsko odmevna in odlično sprejeta v strokovni in širši javnosti, to ni vplivalo na večje zanimanje domačih glasbenih poustvarjalcev za izvajanje na historičnih glasbilih. Med pomembnejšimi vzroki za to je tudi programska usmerjenost visokega glasbenega šolstva, ki dotlej še ni prepoznalo pomena in možnosti tovrstnega poustvarjanja, posledično pa tudi ne nuje izobraževanja v poustvarjalni praksi na historičnih glasbilih. Posamezni slovenski glasbeniki, ki so pokazali zanimanje za koncertiranje na starih glasbilih, so tako odhajali na izobraževanja na tuje visokošolske ustanove, kjer so se večinoma izobraževali kot poustvarjalci na orglah oziroma historičnih instrumentih s tipkami, druga glasbila pa so bila redko predmet poglobljenega zanimanja. Poznamo nekaj primerov interpretacije baročne glasbe na replikah baročnih trobil, ki jih je promoviral vrhunski interpret na trobenti Anton Grčar.

$\mathrm{V}$ zadnjih desetih letih sta restavriranje in javna prezentacija muzejskih glasbil bistveno zastala. Največ vitalnih instrumentov je ohranjenih v nacionalni zbirki glasbil v Pokrajinskem muzeju Ptuj-Ormož, ki je skladno z nacionalnim statusom zbirke in profesionalno relevantnimi projekti uspel uresničiti določene programe revitalizacije glasbene dediščine. V zbirki glasbil je ohranjenih več instrumentov, ki imajo zaradi svojih značilnosti, historičnega izvora, kvalitete in stopnje ohranjenosti poseben pomen. Ob tem se postavlja vprašanje, kako je s posameznimi pomembnejšimi glasbili zbirke v aktualnem času, pa tudi, ali je na Slovenskem skladno z vse večjim pretokom evropskih in svetovnih poustvarjalnih praks zaznati večje zanimanje za instrumentalno dediščino in ustrezno izobraževanje v poustvarjanju, posebno na visoki stopnji. Podrobnejše proučevanje glasbil v ptujski zbirki kaže, da lahko na seznam glasbil, uporabnih v koncertne in druge namene, uvrstimo procesijske orgle celjskega izdelovalca češkega rodu Johanna Frančiška Janečka iz leta 1734, spinet nemške delavnice Neupert iz leta 1936, klavir slovenskega mojstra Andreasa Wittenza (Andrej Bitenc) iz sredine 19. stoletja, klavikord graške delavnice iz sredine 18. stoletja, že omenjeno violo d'amore Johannesa Udalricusa Eberleta iz Prage (1732) in nekatera druga. ${ }^{7}$ Možnosti večjega razvoja historične poustvarjalne prakse torej obstajajo. Med ohranjenimi glasbili je nekaj posebej dragocenih in pomembnih za svetovno dediščino, kar naj bi po pričakovanjih spodbujalo zanimanje poustvarjalcev in vzgojno-izobraževalnih ustanov. Med navedenimi glasbili izpostavljamo izjemno redek Janečkov pozitiv. J. F. Janeček (1700-1777) velja za najpomembnejšega baročnega izdelovalca orgel in utemeljitelja t. i. baročne orglarske šole pri nas. Mojster češkega porekla je v naših krajih utemeljil visoka merila orglarstva in vplival na številne naslednike. ${ }^{8}$ Takšna glasbila so v 17. in 18. stoletju uporabljali pri slovesnih procesijah zunaj cerkve, lahko pa tudi pri krajših liturgičnih obredih. Ker so služila za spremljavo cerkvenemu zboru, imajo registre, primerne za spremljavo petju. Pozitiv je primeren tudi za izvajanje izbrane solistične baročne literature, lahko pa tudi za basso continuo, kot je to potrjeno

6 Koter, Glasbilarstvo na Slovenskem, 146.

7 Koter, Ekspertiza o stanju in možnostih javne prezentacije glasbil v slovenskih muzejih, 5.

8 Škulj, Orgle v Ljubljani, 149. 
s posnetki zbirke Harmonia concertans Isaaca Poscha (1591-1622), izdane leta 1623 in posnete pred dvema desetletjema. ${ }^{9}$

Če se osredotočimo na baročno glasbeno prakso in njene poustvarjalne možnosti na avtentičnih glasbilih, ugotovimo, da v slovenski dediščini ne premoremo historičnega čembala, čeprav so v pisnih virih že od 16. stoletja naprej številni dokazi o lastnikih in rabi. ${ }^{10}$ Vzrokov za to je gotovo več; med najbolj vpijočimi bi lahko izpostavili družbeno-politično pogojene migracijske tokove, ki so vplivali na to, da so se plemiške družine, pogosto glasbeno najdejavnejše, zaradi družbenih in gospodarskih razmer iz slovenskega prostora izseljevale, praviloma pa so s seboj odnašale tudi dragocenejše predmete za osebno rabo, kamor so sodila tudi glasbila. Drugi dejavnik je občutljivost glasbil. Le-ta so ob novih modnih tokovih spravljali v zanje neprimerne prostore, kjer so zaradi vlage in drugih škodljivih dejavnikov propadala. Posledično je glasbena dediščina na slovenskem prostoru skromnejša, kot bi lahko pričakovali v skladu z zgodovino in intenzivnostjo poustvarjalne prakse. Edino ohranjeno glasbilo, ki sodi v družino instrumentov z mehaniko s peresci, kot so čembalo, spinet in virginal, je spinet v ptujskem muzeju. To je izdelek firme Neupert, ki je delovala v kraju Bamberg pri Nürnbergu, iz leta 1936. Ohranjeni primerek sodi v čas, ko se je v svetu poglabljalo zanimanje za historična glasbila, kar je vplivalo na to, da so v priznanih evropskih delavnicah začeli izdelovati njihove replike, na koncertnih odrih pa izvajati glasbo starejših obdobij v slogu nekdanjih manir. Zanimivo in redko je dejstvo, da je tovrstna moda oživljanja historičnih glasbil že v prvi tretjini 20. stoletja, kamor datira obravnavani spinet, prodrla tudi na slovensko območje. Na sedanji stopnji raziskav je to eden redkih znanih primerov, ki dokazuje rabo historičnih glasbil v slovenskem okolju v zgodnjem 20. stoletju. Kljub dokaj bogatim virom, ki potrjujejo prisotnost čembala in njemu sorodnih glasbil v slovenskem okolju od sredine 16. stoletja naprej, ni dokazov, da bi tovrstna glasbila na tem območju tudi izdelovali, kar bi lahko pojasnili s tem, da je potrebe po glasbilih zadovoljevalo dokaj živahno trgovanje s sosednjimi deželami, kjer so bile glasbilarske obrti zelo razvite. ${ }^{11}$

Nekoliko drugače je bilo na področju izdelovanja klavirjev. Prva zlata doba izdelovanja glasbil vseh vrst se je začela ob koncu 18. stoletja. V prvi polovici naslednjega je bilo na primer na Dunaju že okrog 1000 obrtnikov glasbilarjev, med njimi številni izdelovalci klavirjev. ${ }^{12}$ Njihov veliki porast je povezan z razvojem glasbenega šolstva, razmahom poustvarjalne prakse $\mathrm{v}$ družinskem in salonskem okolju in ne nazadnje $\mathrm{z}$ intenzivnejšimi pojavi koncertnega življenja. Vse to je pronicalo tudi v slovensko okolje, ki si je vedno prizadevalo slediti kulturni praksi večjih središč, in Dunaj je bil vzor tudi na tem področju. Čeprav je imel izjemno razvejano in dobro organizirano prodajno mrežo glasbil, so bile potrebe po nekaterih instrumentih tolikšne, da so omogočale preživetje tudi lokalnim mojstrom. V slovenskem prostoru je od konca 18. do sredine 20. stoletja dokazanih 12

9 Prim. Isaac Posch, Harmonia concertans (zvočni CD).

${ }^{10}$ Prim. Koter, Glasbilarstvo na Slovenskem, 117-119; Gardina, »Glasbena dediščina in njeni ustvarjalci«, 52; Kokole, »Glasba plemiških bivališč na Slovenskem od srednjega veka do konca 18. stoletja«, 667-698.

${ }^{11}$ Koter, »Izdelovanje glasbil«, 453-455.

${ }^{12}$ Prim. Hopfner, Wiener Musikinstrumentenmacher 1766-1900. 
izdelovalcev klavirjev. ${ }^{13}$ Med najpomembnejšimi je Ljubljančan Andreas Wittenz, ki je deloval v času od 30. do 60. let 19. stoletja. Čeprav je njegova dediščina izjemno skromna (poleg ptujskega primerka sta v Narodnem muzeju Slovenije ohranjena še dva klavirja), ${ }^{14}$ kaže restavrirani eksponat iz ptujskega muzeja izjemne kvalitete, primerljive z najboljšimi dunajskimi izdelovalci. Wittenz se je obrti izučil v neznani dunajski delavnici, morda celo pri mojstru največjega kova, Ignazu Bösendorferju (deloval med leti 1821 in 1859). ${ }^{15}$ Izvirna ohranjenost Wittenzevega glasbila omogoča avtentično izvajanje romantične glasbene literature velikih imen, kot so Franz Schubert, Robert Schumann, Frédéric Chopin, Franz Liszt idr., kar je v našem okolju edinstvena, a doslej, žal, neizkoriščena možnost. V Pokrajinskem muzeju Maribor hranijo več klavirjev prve polovice 19. stoletja, ki sicer niso restavrirani, vendar bi bili primerni za obnovo. To je za tamkajšnjo ustanovo in glasbeno zgodovino še posebej pomembno, saj je znano, da je v grajski viteški dvorani leta 1846 muziciral sam Franz Liszt. Takšna zgodovinska dejstva naravnost vabijo k ustreznim projektom historične poustvarjalne prakse.

Pri nas ohranjena instrumentalna dediščina omogoča tudi možnosti poustvarjanja v poustvarjalnih manirah klasicizma, saj je med muzejskimi eksponati nekaj klavirjev s kladivci iz konca 18. stoletja. Med njimi izstopa primerek dunajskega izdelovalca Ferdinanda Hofmanna iz leta 1795. To glasbilo ima več pomenov: naj izpostavimo, da je bilo nekoč v lasti slovenskega izdelovalca glasbil Ivana Modica (1912-1991), po njegovi smrti pa je del ptujske zbirke. Poleg tega je pomembno, da njegov izdelovalec klavirjev Ferdinand Hofman (1757-1829) spada med najpomembnejše dunajske mojstre, delujoče na prehodu iz 18. v 19. stoletje. Zgledoval se je pri odličnem Johannu Andreasu Steinu (1728-1792) iz Augsburga, čigar delo je vplivalo na vrsto glasbilarjev tako imenovane dunajske šole v zadnji četrtini 18. stoletja. Po Hofmannovih izdelkih so posegale eminentne plemiške in meščanske družine, pa tudi najvidnejši poustvarjalci. Nekoliko poenostavljeno bi lahko rekli, da so to tako imenovani »Mozart klavirji«, saj je na prav takšne modele Hofmanovih sodobnikov igral Wolfgang Amadeus Mozart. Zanje je značilen obseg 5 oktav $\left(\mathrm{FF}-\mathrm{f}^{3}\right)$, tako imenovana odbojna mehanika z izjemno drobnimi kladivci, ki še ne omogoča hitrega repetiranja oz. ponavljanja tona, dva kolenska vzvoda za niansiranje tona oziroma izvajanje dinamike $\mathrm{v}$ forte in pianu ter lesena uglaševalna deska. ${ }^{16}$ Stanje ptujskega eksponata sicer zahteva temeljite restavratorske posege, po njegovi obnovi pa bi bilo omogočeno izvajanje klasicistične pianistične in komorne literature, ki v klavirskem partu ne presega petih oktav. S tem bi se slovenski glasbeni kulturi odprla možnost edinstvenih poustvarjalnih možnosti, kakršne gojijo najpomembnejši muzeji glasbil na svetu.

Drugi značilni primer je klavir dunajskega mojstra Johanna Krämerja iz časa ok. 1815-1820. To glasbilo je predstavnik klavirjev s posebnimi lastnostmi. Izstopa namreč pedaljera s šestimi nožnimi vzvodi za registre, s katerimi so pianisti niansirali ton. Dva registra sta $\mathrm{s}$ pomočjo letvice $\mathrm{z}$ dušilci omogočala piano in pianissimo, dva ob dvigu dušilcev forte in fortissimo, naslednji pa je tako imenovani Fagotzug. Označuje ga na

\footnotetext{
${ }^{13}$ Koter, Glasbilarstvo na Slovenskem, 120-135.

${ }^{14}$ Prim. Narodni muzej Slovenije, dokumentacija Oddelka za zgodovino in uporabno umetnost.

${ }^{15}$ Koter, Glasbilarstvo na Slovenskem, 130-132.

${ }^{16}$ Prim. Maundner, Keyboard Instruments in Eighteenth-century Vienna, 63-66, 76, 108, 116; Cole, The Pianoforte in the Classical Era, 219, 233.
} 
posebni letvici pritrjena svila, ki je ob skorajšnjem dotiku kladivca omogočala tih in nosljajoč zvok, kot pri fagotu. Zadnji register imenujemo »turška muzika«. To je sinonim za tako imenovano janičarsko kapelo, ki so jo poleg prodornih pihal tipa oboe in trobent sestavljali: veliki bobni, majhne činele, triangli in potresajoče palice z medeninastim okrasjem v obliki turških šotorov s kraguljčki. ${ }^{17}$ Vpliv teh instrumentalnih sestavov se je na začetku 17. stoletja priljubil v avstrijskih vojaških kapelah in skladno z modo turkerij, ki so med drugim posnemale tudi orientalsko glasbo, so skupino tolkal začeli uporabljati v evropskih vojaških godbah. Tako imenovano »turško muziko« so sestavljali: potresajoča palica, činele, triangel in veliki boben. Takšen sestav je med prvimi uporabil W. A. Mozart v operi Beg iz seraja. Proti koncu 18. in v prvih desetletjih 19. stoletja je »turška muzika« postala modni register klavirjev in orgel, in sicer posebno na prostoru nekdanje Avstrije. Pri omenjenem klavirju so register »turške muzike« sestavljali: leseni tolkač, podoben palici za veliki boben, nameščen na spodnji strani ohišja, ki je ob aktiviranju registra udarjal po lesu in imitiral veliki boben. Na levi strani tik ob uglaševalni deski je bil nameščen mehanizem z medeninastimi palčkami in obročki, ki je cingljal in imitiral potresajočo palico s kraguljčki (nem. Schellenbaum, angl. jingling Johny). Čeprav ta mehanizem ni ohranjen, bi ga lahko po vzorih v tujini ohranjenih glasbil obnovili. Klavir $\mathrm{s}$ takšnim registrom je na primer ohranjen v tržaškem muzeju Revoltella. Izdelal ga je Johann (Gionavanni) Heichele, ki je na prehodu iz 18. v 19. stoletje deloval v Ljubljani, nato pa se je preselil v Trst. ${ }^{18}$ Glasbo za klavirje z več registri je v zgodnjem 19. stoletju pisala večina skladateljev širšega nemškega prostora, med njimi tudi L. van Beethoven in F. Schubert. V partiture so redno označevali rabo različnih registrov. Zgovorna primera takšnih skladb sta Beethovnova Koračnica op. 45, št. 1 in Schubertova Vojaška koračnica op. 51 v D-duru, obe za klavir štiriročno. Danes lahko avtentičnost teh skladb slišimo zgolj na historičnih glasbilih ali njihovih replikah, in sicer v interpretaciji pianistov, ki se poglobljeno ukvarjajo s poustvarjanjem v manirah iz časa nastanka skladb.

Med pomembnejšimi godali, ki so ohranjena do te mere, da so usposobljena za izvajanje, je tudi pochette (»žepek«) Françoisa Saraillaca (Lyon, 1679) iz Narodnega muzeja Slovenije, ki je rariteta v svetovnem merilu. Glasbilo sodi med godala, kakršna so skozi 17. in 18. stoletje uporabljali plesni mojstri za poučevanje plesa. Majhen in ozek instrument s podaljšanim vratom ima štiri strune ter šibak in rezek ton. Telo iz javorovega lesa je izdelano v enem kosu (levja glava, vijačnica, vrat in resonančno telo), pokrov je iz smrekove veje. Pri ubiralki, furnirani z ebenovino, je odprtina v obliki srčka, ki nadomešča rozeto, značilno za nekatera večja godala tistega časa. Na pokrovu sta podolgovati zvočnici v obliki črke $C$, prav tako značilni za viole starejšega tipa. Ubiralka, strunek in resonančni pokrov so ob robovih okrašeni z vloženo srebrno žico. Raziskave kažejo, da je bil Saraillac izvrsten mojster ter da se je ohranila le peščica njegovih glasbil. Hranijo jih eminentni muzeji, zato je pochette ali »žepna« violina, kot ji tudi rečemo, še posebnega pomena. ${ }^{19}$ Ker je ugotovljeno, da je Ljubljana že sredi 17. stoletja imela svojega plesnega mojstra, ki je meščane poučeval v plesnih veščinah, je prav mogoče, da je primerek

\footnotetext{
${ }^{17}$ Prim. Ahrens, Hammerklaviere mit Wiener Mechanik, 5-68.

18 Prim. Koter, Glasbilarstvo na Slovenskem, 125-127.

${ }^{19}$ Nav. delo, 141-142, 147-148; prim. tudi Koter, »François Saraillac: Pochette«, 84-85.
} 
povezan s katerim od ljubljanskih plesnih mojstrov. ${ }^{20} \mathrm{Ob}$ oživljanju nekdanjih plesov in plesnih praks, ki smo jim v zadnjih letih priče tudi na slovenskem prostoru, bi veljalo upoštevati tudi pochette kot enega glavnih pričevalcev zgodovine plesa na Slovenskem.

Ob navedenem ugotavljamo, da se slovenski poustvarjalci, specializirani za igranje na historičnih glasbilih ali njihovih replikah, le izjemoma zanimajo za domačo dediščino. Eden izmed vzrokov za to je, da pomen muzejskih glasbil, ki so usposobljena za javno rabo, v širši javnosti ni dovolj prisoten. Čeprav je bilo v zadnjih dvajsetih letih v domačih in mednarodnih publikacijah objavljenih precej študij, ki opozarjajo nanje, posamezni muzeji pa so posamezna glasbila promovirali na javnih prireditvah, koncertih in zgoščenkah, to ni spodbudilo sodelovanja. Primerne korake bi bilo torej potrebno storiti na več področjih. Muzeji naj bi posamezna glasbila načrtno restavrirali in jih promovirali. Z izvirnimi idejami bi se lahko odprlo tesno sodelovanje s festivali, snovalci koncertnih ciklov in izobraževalnimi institucijami. Posebej pa velja izpostaviti, da bi intenzivnejše pojavljanje starih glasbil v javnosti spodbudilo nove raziskave in primerjave s svetovno dediščino, ne nazadnje pa tudi večjo prepoznavnost v mednarodnih krogih. Poleg tega je v svetu že dolgo uveljavljena praksa, da sodobni skladatelji ustvarjajo tudi za historična glasbila, ki v današnjem času predstavljajo poseben umetniški izziv.

V zadnjih desetletjih so se na Slovenskem utrdili festivali in koncertni cikli za staro glasbo, nastali so posamezni ansambli, vrstijo se gostovanja priznanih umetnikov, trendu oživljanja nekdanjih poustvarjalnih praks pa so pripomogli tudi muzejski glasbenopedagoški programi. ki vključujejo obiske muzejev in koncertov stare glasbe. Pomembno je tudi izobraževanje na visoki ravni. Na Akademiji za glasbo Univerze v Ljubljani je bila z uvedbo bolonjskih programov ustanovljena Katedra za staro glasbo, v okviru katere se študenti urijo v igranju historičnih glasbil. To so sicer šele prvi koraki, ki pa lahko po vzoru nekaterih uspešnih univerz v svetu vplivajo na razširjanje tovrstnih dejavnosti. Ljubljanska Akademija je doslej pripravila nekaj odmevnih koncertov stare glasbe in uprizoritev oper 17. in 18. stoletja. Med najodmevnejšimi projekti sta izvedbi Monteverdijeve opere Orfej (2012) in La Cecchina ali Nikogaršnja hči Niccola Piccinija (2014). Obe predstavi sta bili v strokovnih in laičnih krogih dobro sprejeti.

Vprašanja o poustvarjalnih manirah preteklih obdobjih vedno znova zaposlujejo interprete na avtentičnih glasbilih oziroma njihovih replikah in tudi tiste, ki so predani sodobni izvajalski praksi na aktualnih instrumentih. Kot je znano, je bila še na začetku 19. stoletja poustvarjalna praksa naravnana predvsem na izvajanje novih del, zato so bile številne skladbe za interprete nezanimive in posledično pozabljene. S takšnim odnosom do glasbene preteklosti je šla v pozabo tradicija izvajanja, z njo pa so se izgubljale tudi oblike nekdanjih glasbil. Danes glasbo srednjeveške dobe, renesanse, baroka in klasicizma pogosto imenujemo stara glasba (v angleško govorečem prostoru je uveljavljen izraz early music), pojem pa se razširja tudi na romantiko. Interpreti stare glasbe se poglabljajo v izvirne partiture, uporabljajo historična glasbila in ne nazadnje interpretirajo manire preteklih dob, s čimer je oživljena tudi istočasna estetika glasbe. V zadnjih desetletjih so nekdanje izvajalske manire in značilnosti historičnih glasbil dodobra raziskali, zato je vse manj neznank in približnih interpretacij. Nekatera glasbila so se bistveno spremenila po

${ }^{20}$ Prim. Mal, Stara Ljubljana in njeni ljudje, 117-119; Žvanut, Od viteza do gospoda, 70. 
letu 1820, ko so na primer razvili sistem mehanike z ventili pri trobilih in tako imenovano Böhmovo mehaniko pri pihalih, s čimer so instrumenti dobili širši tonski obseg, čistejšo intonacijo, boljše akustične značilnosti in ne nazadnje tehnično izpopolnjeno mehaniko. ${ }^{21}$ Nasprotno od pihal in trobil je razvoj nekaterih drugih glasbil, posebno klavirja, od druge polovice 18. stoletja potekal po manjših korakih, vendar neprekinjeno. Izdelovalci in poustvarjalci so posebno od 17. stoletja naprej tesno sodelovali in vzajemno razvijali nove oblike glasbil, izpopolnjene $\mathrm{v}$ oblikah, mehaniki, tonskem obsegu in ne nazadnje v zvočnih možnostih. To je bilo posebno očitno pri klavirski glasbi. Za Beethovna na primer velja, da je bil pri tehničnih in zvokovnih možnostih klavirjev precej pikolovski in nezadovoljen. Prav tako vemo, da je vplival na bistvene novosti v mehaniki, razširitvi obsega klavirja in na polnejši zvok. Sicer velja, da je Beethoven v zgodnjem ustvarjalnem obdobju pisal za klavirje s petimi oktavami, tako kot pred njim Mozart in drugi, po letu 1820 , ko se je obseg razširil, za šest oktav in več. ${ }^{22} \mathrm{O}$ interpretaciji Beethovnovih klavirskih sonat je še danes precej deljenih mnenj, a razlaga teh bi zahtevala posebno obravnavo. Oživljanje avtentičnih notnih zapisov in igranje na glasbila, skladna s časom nastanka del, se je začelo proti koncu 19. stoletja. Med pionirji, ki so se začeli zavedati razkorakov med izvirniki in kasnejšimi tiski, je bil Friedrich Chrysander (1826-1901). S svojimi razmišljanji je sprožil val raziskav o avtentičnosti stare glasbe. Skladno z njegovimi prizadevanji so najbolj vneti privrženci avtentike začeli izvajati glasbo na starih glasbilih, kar je med drugim vplivalo na zavedanje pomena ohranjanja starih glasbil, pa tudi na izdelovanje replik. Med glasbeniki so se o tem vnele žolčne razprave in dolgo je veljalo, da je gibanje za staro glasbo zgolj eksperimentiranje, ki nima prihodnosti. ${ }^{23}$

Eden pomembnejših zagovornikov poustvarjalnosti na izvirnih glasbilih ali njihovih replikah je bil Arnold Dolmetsch (1858-1940), delujoč v Angliji, ki je imel od konca 19. stoletja naprej velik vpliv na proučevanje starih partitur in njihovo izvajanje. Posebno se je poglabljal v rekonstrukcijo glasbil, ki jih v njegovem času niso več v uporabljali (viole da braccio, viole da gamba, viole d'amore, blok flavte, šalmaji, bombarde, instrumenti s tipkami, kot so čembalo, spinet, virginal in klavikord, med brenkali lutnje in harfe). Zanj velja, da je bil vsestranski pionir izvajanja stare glasbe. Dosežke svojega študija, poustvarjalne prakse in izdelovanja glasbil je na začetku 20. stoletja prenesel tudi v Združene države Amerike, kjer so številni glasbeniki sledili njegovim načelom. Leta 1915 je na podlagi večletnega študijskega in znanstvenega poglabljanja v problematiko izšla njegova razprava z naslovom Interpretacije glasbe 17. in 18. stoletja, ki je postala temeljno delo za številne posnemovalce in naslednike. ${ }^{24}$

Večji razmah je poustvarjanje v historičnih manirah doživelo v drugi polovici 20 . stoletja, na kar so močno vplivali dirigent Nikolaus Harnoncourt in številni drugi, ki so ustanavljali ansamble za staro glasbo povsod po Evropi in dosegali priznanja strokovnih in laičnih krogov. Odtlej je ta praksa, ki se je neprestano razvijala in spreminjala, postala del

${ }^{21}$ Prim. Heyde, Das Ventilblasinstrument; Dullat, Holzblasinstrumentenbau; Baines, Brass Instruments.

22 Prim. Cole, The Pianoforte in the Classical Era, 135-143, 218-219, 273-275.

${ }^{23}$ Prim. Taruskin, »The pastness of the present and the presence of the past«, 137-207.

${ }^{24}$ Dolmetsch, The Interpretation of the Music of the 17th and 18th Centuries Revealed by Contemporary Evidence. 
glasbene kulture in predmet novih proučevanj, ki so dala številna znanstvena spoznanja o preteklih dobah, posebno o zasedbah, instrumentih in njihovih zmožnostih, načinih igranja ali petja, ne nazadnje pa so prinesla tudi ugotovitve o interpretaciji in glasbeni estetiki nekdanjih dob. Vse to je pripomoglo k boljšemu poznavanju glasbe starejšega časa in vplivalo na to, da se je zanimanje za historično poustvarjalnost stopnjevalo in ni presahnilo. Nasprotno: v svetu so nastali številni glasbeni festivali, ki se posvečajo stari glasbi, naraščajo medijske založbe, vse več pa je tudi specializiranih restavratorjev glasbil in izdelovalcev njihovih replik.

Danes so glasbeniki avtentičnim partituram in zapisom o izvajanju v času nastanka del mnogo bolj naklonjeni kot nekoč. Številni interpreti se zavedajo razkoraka med prvinsko partituro in izvedbo ter problematike številnih prepisov, ki so izvirnike spreminjali v zasedbi, dinamiki, agogiki in še čem. Zato se pri študiju partitur temeljito poglabljajo v izvirnike, slogovne značilnosti ter v interpretativne in estetske kriterije. Ob tem se sprašujejo, kakšna so bila glasbila prvih izvedb, tako po obliki, mehaniki, obsegu, pa tudi zvoku, ki je prav tako izjemno pomemben segment študija in oživljanja nekdanjih praks. Skladno s časom so nastajala nova glasbila, in sicer s povsem drugačnimi značilnostmi zvoka in načini igranja. Vse to so pomembni dejavniki, ki jih je potrebno upoštevati, če se želimo približati nekdanjim poustvarjalnim maniram.

Ob povedanem se odpirajo vprašanja o tem, kako so se nekdanje poustvarjalne prakse pojavljale in razvijale na Slovenskem. Raziskave kažejo, da so se najprej začeli zavedati pomena ohranjanja historičnih glasbil. Na to kaže dediščina starih glasbil v Pokrajinskem muzeju Ptuj-Ormož. Tamkajšnja zbirka glasbil je začela nastajati kmalu po ustanovitvi muzeja leta 1893. Že dve leti kasneje je muzej pridobil bogato zbirko različnih predmetov umetnih obrti. Ptujčanom jo je podaril polihistor Franz Ferk (1844-1925), doma iz Gomilice (danes Gamlitz) pri Gradcu. Med dva tisoč predmeti je bilo tudi okrog štirideset glasbil: klavirji, godala, brenkala, pihala in trobila iz poznega 18. in zgodnjega 19. stoletja ter nekaj ljudskih glasbil, vsa iz širšega prostora nekdanje avstrijske monarhije. Ptujski muzealci so se začeli zavedati, da so tudi glasbila del kulturne dediščine, zato so si po Ferkovem vzoru prizadevali, da bi zbirko glasbil dopolnili s predmeti lokalnega okolja. $\mathrm{Z}$ nakupi, darili in volili so uspeli pridobiti predvsem glasbila ptujskih godbenikov, med katerimi je nekaj izvrstnih instrumentov dunajskih in na Slovenskem delujočih glasbilarjev. Intenzivnejše in načrtno zbiranje glasbil iz širšega slovenskega prostora se je v ptujskem muzeju začelo okrog leta $1990 .^{25}$

Prve objave o ptujski glasbeni zbirki pripisujemo učitelju in vsestranskemu glasbeniku Hinku Druzoviču (1873-1959). Njegovo poročilo iz leta 1938, ki sicer nima znanstvenih razlag, je bilo namenjeno utrjevanju pomena kulturne dediščine. ${ }^{26}$ Posledično je bilo nekaj najpomembnejših eksponatov ptujske zbirke leta 1932 razstavljenih na prvi slovenski glasbeni razstavi ob 60-letnici ljubljanske Glasbene matice, katere promotor je bil Josip Mantuani (1860-1933), umetnostni zgodovinar, arheolog in ne nazadnje glasbeni zgodovinar. ${ }^{27}$ Žal je bila ta razstava, ki je sicer predstavila širšo slovensko glasbeno ustvarjalnost in poustvarjalnost, le enkratno dejanje brez trajnih rezultatov. Podobna razstava se namreč

${ }^{25}$ Koter, Glasbilarstvo na Slovenskem, 8-12.

${ }^{26}$ Druzovič, »Iz ptujske glasbene preteklosti«, 171-177.

${ }^{27}$ Mantuani, Razvoj glasbe pri Slovencih. 
do danes ni ponovila. Težko je reči, da je Mantuanijeva gesta predstavitve glasbil vplivala na njihovo pospešeno zbiranje in ohranjanje, saj o tem ni ohranjenih virov. Glasbila so v slovenske muzeje še naprej prihajala bolj kot ne slučajno: $z$ darili, volili in deloma nakupi. Nekoliko drugače je bilo v ptujskem muzeju, posebno od konca 50. let dalje. Takrat je za zbirko skrbel učitelj in glasbenik Drago Hasl (1900-1976). S svojo razgledanostjo je vplival na nove pridobitve, še posebno na ljudska glasbila iz Haloz. S pomočjo prijateljev diplomatov, ki so bili tako ali drugače povezani s Ptujem, pa je zasnoval tudi zbirko neevropskih glasbil iz Azije, Afrike, Indonezije, Kitajske in od drugod. V muzeju je postavil prvo stalno razstavo glasbil, s katero je ustanova še bolj opozarjala na tovrstno dediščino in historična glasbila. Njegovo delo je prineslo trajne rezultate in še večjo skrb za zbiranje, dokumentiranje, restavriranje in prezentiranje glasbene dediščine. Drago Hasl je napisal tudi pomembno razpravo o haloški žvegli. ${ }^{28}$

In kako kaže glasbeni poustvarjalni praksi z zvenom historičnosti v slovenskem okolju v prihodnje? S povedanim smo želeli opozoriti na glasbeno instrumentalno dediščino, njen vsestranski pomen in možnosti za izvajanje ter na to, da je v domačem kulturnem okolju nekaj izjemnih glasbil, primernih za koncertno igranje, ki pa niso ustrezno opažena in promovirana. Prav tako je bilo izvzetih nekaj primerov glasbil, ki s svojimi edinstvenimi kvalitetami predstavljajo poseben restavratorski izziv za prihodnost. Intenzivnejše oživljanje nekdanjih glasbenih praks zahteva sodelovanje različnih akterjev, muzejskih krogov, ustreznih državnih institucij in ne nazadnje glasbenih poustvarjalcev stare glasbe. Čeprav so znanstvene raziskave glasbil dokaj številne, ${ }^{29}$ vsakokratno poglabljanje v kulturno dediščino izzove nove raziskave in ugotovitve. Če se naslonimo na aktualno raziskavo o prisotnosti in stanju historičnih glasbil v slovenskih muzejih, izluščimo tudi potrebe po izdelovanju replik, s katerimi zaščitimo izvirnike. Ne nazadnje je potrebno omeniti, da je izvajanje stare glasbe pogosto prepleteno z drugimi elementi kulturne dediščine, kot so slavnostne dvorane v gradovih in palačah, cerkveni hrami, historični trgi in dvorišča. Stara mestna jedra in drugi arhitekturni spomeniki v sinergiji z različnimi umetnostmi postajajo prostor aktualne poustvarjalnosti in del žive kulture. Najpomembnejši trajnostni cilj, povezan s historičnimi glasbili, se navezuje na izobraževanje, katerega temeljni člen je oblikovanje vrednot in tankočuten odnos do kulturne dediščine. Če bomo glasbeno

${ }^{28}$ Hasl, »Haloška žvegla«.

${ }^{29}$ Navajam nekaj pomembnejših objav: Darja Koter, »Musikinstrumente österreichischer Klavierbauer im Landesmuseum Ptuj / Pettau (Slowenien)«, Muzikološki zbornik 33 (1997): 65-80; ista, »Izdelovalci pihal na Slovenskem in njihova dediščina«, Muzikološki zbornik 35 (1999): 147-165; ista, Glasbilarstvo na Slovenskem (gl. literaturo); ista, »Izdelovalci glasbil na Slovenskem 1606-1918«, Muzikološki zbornik 39 (2003): 123-152; ista, »Entwicklung der Bläsermusik und des Instrumentenbaus in Slowenien«, v: Wege der Bläsermusik im südöstlichen Europa, ur. Friedhelm Brusniak in Klaus-Peter Koch, Arolser Beiträge zur Musikforschung, zv. 10 (Sinzig: Studio Verlag, 2004), 49-65; ista, »The interdependence of instrument making in Slovenija with other European movements«, v: Musikinstrumentenbau im interkulturellen Diskurs, ur. Erik Fischer, Annelie Kürsten in Sarah Brasack, Berichte des interkulturellen Forschungprojekts 'Deutsche Musikkultur im östlichen Europa', zv. 1 (Stuttgart: Franz Steiner, 2006), 13-32; ista, »Baroque organ cases with angelic musicians: Johann Frančišek Janeček and the embellishment at his organs «, Hudebni věda 46 (2009): 241-260; ista, »Iz glasbene dediščine tuštanjske graščine«, Kronika 57, št. 2 (2009): 357-364. 
zapuščino slovenskih muzejev v prihodnje bolje promovirali in jo povezovali s poustvarjalno prakso, bo to gotovo spodbudilo nadaljnji razvoj glasbenega izobraževanja. Prihodnost sloni tudi na študentih Akademije za glasbo, ki skladno z možnostmi že med študijem snujejo ansamble za staro glasbo in z njimi uspešno nastopajo, s čimer kažejo pot akademskim in muzejskim krogom ter organizatorjem koncertne dejavnosti na širšem slovenskem prostoru.

\section{Uporabljena literatura}

Ahrens, Christian. Hammerklaviere mit Wiener Mechanik. Frankfurt na Majni: Bochinsky Verlag, 1999.

Baines, Antony. Brass Instruments: Their History and Development. New York: Dover Piblications, Inc., 1993.

Cole, Michael. The Pianoforte in the Classical Era. Oxford: Clarendon Press, 1998.

Dolmetsch, Arnold. The Interpretation of the Music of the 17th and 18th Centuries Revealed by Contemporary Evidence. London: Novello, 1915.

Donington, Robert. The Interpretation of Early Music. London: Faber and Faber, 1963.

Dreyfus, Laurence. »Early Music defended against its devotees: a theory of historical performance in the twentieth century«. Musical Quarterly 69, št. 3 (1983): 297-322.

Druzovič, Hinko. »Iz ptujske glasbene preteklosti«. Kronika slovenskih mest 5, št. 3 (1938): 171-177.

Dullat, Günter. Holzblasinstrumentenbau: Entwicklunsstufen und Technologien. Celle: Edition Moeck, 1990.

Gardina, Helena. »Glasbena dediščina in njeni ustvarjalci«. V: Musica aeterna est: Glasbeno življenje v slovenskih obalnih mestih do 19. stoletja, ur. Vlasta Beltram, 37-56. Koper: Pokrajinski muzej, 2006.

Hasl, Drago. »Haloška žvegla«. Traditiones 4 (1975): 89-116.

Heyde, Herbert. Das Ventilblasinstrument: Seine Entwicklung im deutschsprachingen Raum von den Anfängen bis zur Gegenwart. Wiesbaden: Breitkopf \& Härtel, 1987.

Hopfner, Rudolf. Wiener Musikinstrumentenmacher 1766-1900: Adressenverzeichnis und Bibliographie. Tutzing: Hans Schneider, 1999.

Kenyon, Nicholas, ur. Authenticity and early music. Oxford: Oxford University Press, 1988.

Kokole, Metoda. »Glasba plemiških bivališč na Slovenskem od srednjega veka do konca 18. Stoletja«. Kronika 60 (2012): 667-698.

Koter, Darja. Ekspertiza o stanju in možnostih javne prezentacije glasbil v slovenskih muzejih. Ljubljana, 2014 (tipkopis).

. »François Saraillac: Pochette«. V: Theatrum vitae et mortis humanae: podobe iz 17. stoletja na Slovenskem, ur. Maja Lozar Štamcar in Maja Žvanut, 84-85. Ljubljana: Narodni muzej Slovenije, 2002.

___ Glasbilarstvo na Slovenskem. Maribor: Založba Obzorja, 2001.

»Izdelovanje glasbil«. V: Glasba na Slovenskem do konca 16. stoletja, ur. Jurij Snoj. Zgodovina glasbe na Slovenskem, zv. 1, 443-459. Ljubljana: Založba ZRC, 2012. 
Lawson, Colin, in Robert Stowell. The Historical Performance of Music. An Introduction.

Cambridge: Cambridge University Press, 1999.

Mal, Josip. Stara Ljubljana in njeni ljudje. Ljubljana: DZS, 1957.

Mantuani, Josip. Razvoj glasbe pri Slovencih. Katalog razstave. Ljubljana: Glasbena matica, 1932.

Maundner, Richard. Keyboard Instruments in Eighteenth-century Vienna. Oxford: Clarendon Press, 1998.

Posch, Isaac. Harmonia concertans, izvaja Ramovš consort. Ljubljana: Klemen Ramovš Management, 1994 (zvočni CD).

Škulj, Edo. Orgle v Ljubljani. Celje: Mohorjeva družba, 1994.

Taruskin, Richard. »The pastness of the present and the presence of the past «. V: Authenticity and early music: a symposium, ur. Nicholas Kenyon, 137-207. Oxford: Oxford University Press, 1988.

Žvanut, Maja. Od viteza do gospoda. Ljubljana: Viharnik in Znanstveni inštitut Filozofske fakultete, 1994.

\section{HISTORICAL MUSICAL INSTRUMENTS IN PERFORMANCE PRACTICE POSSIBILITIES AND PERSPECTIVES IN SLOVENE MUSIC CULTURE}

\section{Summary}

The present article focuses on the way in which performance practice with the historical musical instruments kept in Slovene museums has developed until the present day as well as its potential development. In Slovenia, there has been little interest in such performance practice despite the many available opportunities for it. In some parts of Europe, the interest in studying early performance practices, and consequently in collecting, preserving and performing on early instruments, began to grow in the 19th century. In Slovenia, awareness of the significance of early musical instrument preservation developed at the end of the 19th century, while historically informed performances appeared in the late 1980s. It has been steadily increasing since then. However, there is a mismatch between the development of such practices and the cultural heritage potential, which can be ascribed to a number of factors: insufficient knowledge of musical heritage and the dynamics of restoration; insufficient promotion of museum collections and particular instruments and flaws in music education. Educational institutions could implement adequate study programmes in order to influence performance possibilities and consequently the promotion of musical heritage. Recent research on musical heritage and historical instruments, as well as on their condition and on the significance of museum collections of musical instruments, has found that Slovene museums have some instruments in their collections which are of national and international cultural significance. Furthermore, it was also found that some of them are in a playable state and therefore suitable for concert performance. The research reveals that musical exhibits of importance are held in the collections of the following regional museums: Ptuj-Ormož, Maribor, Celje and Koper, 
the National Museum of Slovenia, the Museum of the Posavje Region in Brežice and the Sergej Mašera Maritime Museum in Piran. Among other things, the research has highlighted the importance of restoration and handling issues regarding musical exhibits and also pointed to the fact that these collections hold some instruments that, after appropriate restorative procedures, could become suitable for artistic creation. Current developments have fuelled the discussions about such issues, which have resulted in the implementation of a number of initiatives. The museum profession predominantly advocates the enforcing of special regulations that would define the conditions under which the individual exhibits could be used for public purposes, lent, or presented sound wise. Nevertheless, it should be noted that certain participants in concert performing and some early music festival organizers may be unaware of the special requirements and sensitivity of musical instruments from museum collections. On the basis of negative experiences in this regard, replicas that offer an appropriate substitute for the originals are being made worldwide; however, in Slovenia, such practice is still rare. Early musical practices cannot be more widely revived without the cooperation of a range of participants, such as the museum sector and relevant state institutions. Increased interest among musicians - performers of early music is also expected. Until now, several studies concerning Slovenian musical instrument heritage have been carried out and even though they have confirmed the significance of this heritage within the international context, every investigation into cultural heritage leads to further research and a new set of conclusions. Current research on the historical instruments (including their condition) held in Slovene museums indicates that early music performance is often intertwined with other elements of cultural heritage, such as festival halls in castles and mansions, churches, historic squares and backyards. Historic town centers and other architectural monuments are, in synergy with a variety of arts, becoming sites for fresh artistic interpretations and performances and therefore part of living culture. The most important goal within the sustainable approach to historical instruments is related to education, as it is founded principally on imparting the values of, and a sensitive approach to, cultural heritage. In the future, we should improve the promotion of the musical heritage kept in Slovenian museums and associate it with performance practice, as this would definitely encourage the development of music education already in place at the Academy of Music of the University of Ljubljana. Slovene students are given the opportunity to set up early music ensembles and perform (usually successfully) during their studies; by doing so, they clearly indicate the path that the Academy, museum institutions and concert organizers in the wider Slovene area should follow. 